\title{
Evaluating the Efficacy of a Pre-Intern Training Programme on Essential Clinical Skills
}

\author{
Padeniya PSMAB ${ }^{1}$, Heenatigala $\mathrm{CSN}^{2}$, Pieris $\mathrm{KVM}^{2}$, Epitakaduwa $\mathrm{DC}^{3}$ and Ranasinghe $\mathrm{D}^{3 *}$ \\ ${ }^{1}$ Paediatric neurologist, Lady Ridgeway Hospital for children, Sri Lanka \\ ${ }^{2}$ Faculty of Medicine, University of Colombo, Sri Lanka \\ ${ }^{3}$ Society for Health Research and Innovation (SHRI), Sri Lanka
}

Submission: September 15, 2017; Published: October 23, 2017

*Corresponding author: Ranasinghe D, Society for Health Research and Innovation (SHRI), Email: dineshanrana2000@yahoo.com

\section{Introduction and Objectives}

Internship is the bridging stone for medical graduates to become medical professionals. In Sri Lankan context there's a delay of nearly one year from completion of the medical degree to the commencement of internship, which is not ideal. The aim of this study was to ascertain the effectiveness of a training programme devoted to revise the essential clinical skills of preintern medical officers in Sri Lanka.

\section{Method}

A descriptive cross sectional study was done among preintern medical officers in Sri Lanka in collaboration with a 5 day clinical skills training programme in October, 2014. The data was extracted from a pre and post assessment online data form.

Results

A total of 1089 pre-interns were included in the study. Out of the clinical skills they were trained on, there was a statistically significant improvement $(p<0.05)$ on the self- perceived competency in many procedures including suturing, nasogastric tube insertion, catheterization, monitoring with Glasgow coma scale, cannulation, infusion pump setup, blood and blood products transfusion, removal of inter costal tube, giving injections, lumbar puncture, airway maneuvers, intubation, cardio-pulmonary resuscitation, defibrillation, arterial puncture, wound dressing, suture removal, bandaging, nebulization and connecting to an ECG monitor. There was no significant difference ( $p>0.05$ ) in self-perceived competency on few procedures including venepuncture, glucometer use, pleural and peritoneal tap.

\section{Conclusion}

Pre-intern medical officers lacked self-perceived competency on many essential clinical skills which significantly improved following a training programme. It is important to promote and sustain pre-intern training programmes in order to improve patient outcome through junior doctors.
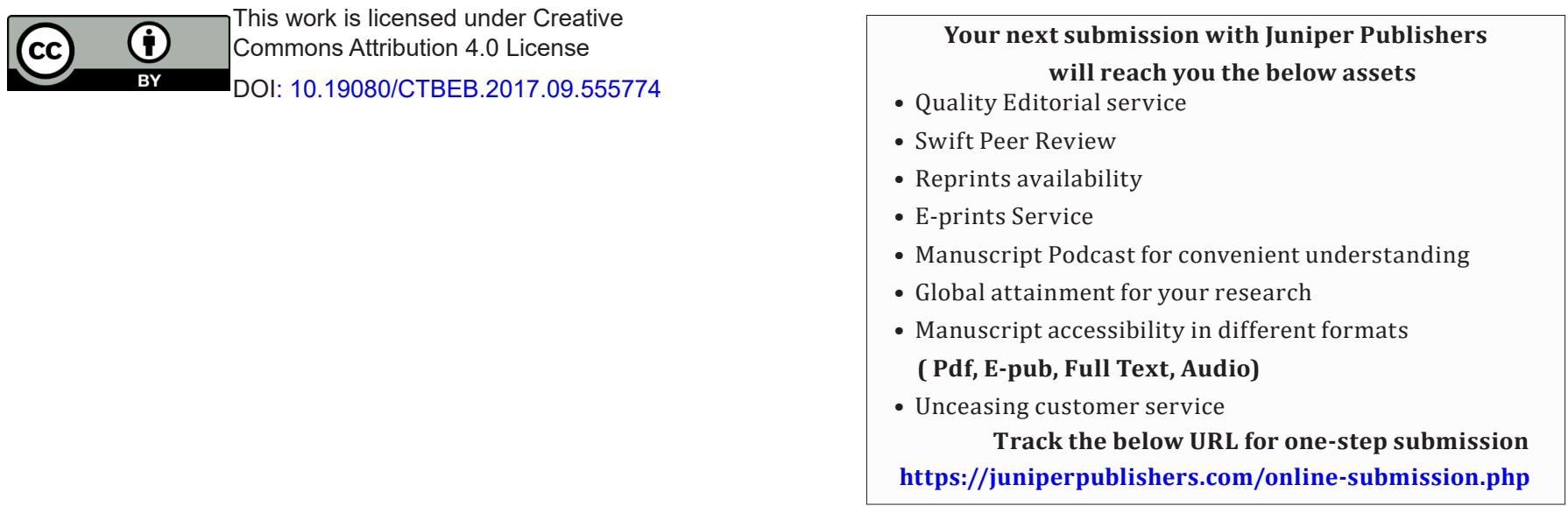